\title{
Relação entre índice de qualidade das águas e densidade demográfica dasimétrica em igarapés urbanos Amazônicos
}

A urbanização insustentável acarreta números impactos ambientais, o que acaba repercutindo na depleção da qualidade ambiental, particularmente nas águas superficiais urbanas. Estudos relacionando a densidade demográfica à qualidade da água ainda são escassos. Diante disso, o objetivo da presente pesquisa foi avaliar a qualidade das águas urbanas em Ji-Paraná (RO) e identificar as relações existentes entre a densidade demográfica dasimétrica e o Índice de Qualidade das Águas (IQA) em seus igarapés urbanos. Nas etapas metodológicas foram selecionados 10 diferentes postos de amostragem em setores censitários de distintas classes de densidade demográfica, resultantes da interpolação de dados orbitais e censitários, sendo que para cada posto foram aferidos os IQA nos períodos chuvoso, vazante, estiagem e enchente, perfazendo 8 campanhas de coletas. As amostras foram caracterizadas por meio de análises físicas, químicas e microbiológicas consoantes com normas nacionais (NBR/ABNT) e internacionais (SM/APHA). Por fim, os valores de densidade demográfica dasimétrica foram correlacionados estatisticamente com os de IQA, por meio da correlação de Pearson. De acordo com os resultados obtidos, a área de estudo possui uma amplitude na densidade demográfica dasimétrica de 6976 habitante $/ \mathrm{km}^{2}$; foi evidenciada baixa qualidade dos igarapés urbanos, grande parte dos postos apresentaram IQA na classe péssima e ruim nos quatro períodos, sobretudo nos de enchente e chuvoso, e o período vazante apresentou maior sensibilidade de correlação, com valor de $\rho=-0,75$, enquanto os demais períodos apresentaram fraca correlação negativa. As correlações negativas da densidade demográfica dasimétrica com o IQA indicam uma relação de depleção na qualidade da água superficial urbana em decorrência do aumento da concentração populacional, conquanto sejam diversos e complexos os aspectos envolvidos nesse vínculo.

Palavras-chave: Dasimetria; IQA; Análises físico-químicas; Amazônia Ocidental; Pressão antrópica.

\section{Relation between water quality index and dasymetric population density in urban Amazonian Streams}

The unsustainable urbanization provides several environmental impacts, which contribute to the reduction of the environmental quality, particularly in urban surface waters. There are few studies that approach the relation between demographic density and water quality. Thus, this scientific work has the objective of evaluate the quality of urban waters from the city Ji-Paraná (RO) and identifying the relations between dasymetric demographic density and Water Quality Index (WQI) in urban Amazonian streams. In the methodological stages, 10 distincts sampling stations of census tracts with different demographic density classes were selected, resulting from interpolation of orbital and census data, and for each station the WQI were measured in the rainy season, ebb, drought and flood, totaling 8 collection campaigns. The samples were characterized by physical, chemical and microbiological analyses in compliance with national (NBR) and international standards (APHA). Finally, the values of dasymetric demographic density were statistically correlated to those of WQI, by means of Pearson's correlation. According to the obtained results, the city of Ji-Paraná has a amplitude at dasymetric demographic density of 6976 inhabitants/ $\mathrm{km}^{2}$; there is a low quality in urban Amazonian streams, most of the stations presented WQI in the class very bad and bad in the four season, especially those of flood and rainy, and the ebb period presented higher sensitivity of correlation, with $\rho=-0,75$, while the other periods presented a low negative correlation. The negative correlations of the dasymetric demographic density with the WQI indicate a relationship of depletion in urban surface water quality due to the increase in population concentration, although the aspects involved in this link are diverse and complex.

Keywords: Dasymetric map; WQI; Physicochemical analysis; Western Amazon; Anthropogenic pressure.

Topic: Engenharia de Recursos Hídricos

Reviewed anonymously in the process of blind peer.
Received: 14/12/2017

Approved: 24/01/2018
Victor Nathan Lima da Rocha (ii)

Universidade Federal da Paraíba, Brasil

http://lattes.cnpq.br/5022112931485478

http://orcid.org/0000-0002-6736-2538

victornathan.eng@gmail.com

Nara Luísa Reis de Andrade (ic)

Universidade Federal de Rondônia, Brasil

http://lattes.cnpq.br/1976520958836915

http://orcid.org/0000-0001-8602-6161

naraluisar@unir.br
Referencing this:

ROCHA, V. N. L.; ANDRADE, N. L. R.. Relação entre índice de qualidade das águas e densidade demográfica dasimétrica em igarapés urbanos Amazônicos. Revista Ibero Americana de Ciências Ambientais, v.9, n.2, p.148-159, 2018. DOI: http://doi.org/10.6008/CBPC2179$\underline{6858.2018 .002 .0013}$ 


\section{INTRODUÇÃO}

A oferta de água no que tange aos seus aspectos quali-quantitativos está intrinsicamente relacionada à economia, ao lazer e bem-estar, à saúde ambiental e pública, às questões sociais e culturais, e à biodiversidade da localidade. Com a expansão demográfica e melhoria nos índices de qualidade de vida da população, é também crescente a demanda de água para suprir suas necessidades. Em contrapartida, a eficiência na forma do uso da água não acompanha esses índices, acarretando diversos impactos ambientais oriundos de uma gestão não integrada e insustentável deste recurso. Uma gestão insustentável que, atrelada à urbanização desordenada, abarca inúmeros aspectos ambientais, tais como impermeabilização do solo, excessivo adensamento populacional, alta exploração dos recursos naturais, descarga de efluentes e resíduos sólidos, dentre outros; o que acaba repercutindo na depleção da qualidade das águas (BOLLMANN et al., 2006; FIA et al., 2015; GARCIAS, 2016; LEMOS et al., 2010; MENEZES et al., 2016).

Esses impactos ambientais são mais acentuados em águas urbanas, em razão do contato direto em áreas de densa população humana, que são receptáculos de esgotos domésticos e industriais e resíduos sólidos urbanos (FIA et al., 2015). Sob esta perspectiva, Gorski (2010) salienta que "os rios urbanos têm sua condição de deterioração agravada pela precariedade do saneamento básico, pela crescente poluição ambiental, pelas alterações (pontuais ou no âmbito da bacia hidrográfica) da condição hidrológica e morfológica bem como pela ocupação irregular de suas margens".

Evidencia-se, portanto, a necessidade de monitoramento da qualidade desses corpos hídrico por meio de variáveis físicas, químicas e microbiológicas da água para avaliação e compreensão da influência das ações antrópicas sobre o meio, o que permite buscar medidas de intervenção ou de mitigação destes problemas. Uma alternativa para avaliação da qualidade da água é o Índice de Qualidade das Águas Superficiais (IQA). Segundo Maane-messai et al. (2010), alguns estudos têm utilizado esse índice, elaborado a partir de uma relação matemática que transforma várias análises dos parâmetros físico-químicos e microbiológicos da água em um único número, facilitando assim a avaliação de sua qualidade.

Nesta linha de pensamento, Oliveira (2012) destaca sua importância em decisões de gestão em bacias hidrográficas, pois "desempenha um papel importante na tradução do monitoramento, por ser uma ferramenta de comunicação simples para transferência de dados de qualidade de água superficiais". Com aplicabilidade inclusive no cenário nacional urbano (DAMASCENO et al., 2015; LOPES et al., 2008; MORAIS et al., 2009; PEREIRA et al., 2013; PINTO FILHO et al., 2008; SILVA et al., 2013).

Conquanto, Bollmann et al. (2006) afirmam que "apesar da abundância de textos disponibilizados na literatura que procuram medir quantitativamente as concentrações de poluentes nos rios urbanos, relativamente pouca atenção tem sido dedicada às relações entre estas concentrações e a densidade populacional". Tal fator é de extrema relevância, especialmente em cidades amazônicas, nas quais a presença de nascentes e corpos hídricos compõe a paisagem urbana. É importante caracterizar que, na Amazônia, cursos d'água superficiais, de até 3a ordem, recebem denominação de igarapés (ANA, 2015; BRITANNICA, 2017; FIDELIS et al., 2008). 
Neste contexto, o objetivo da presente pesquisa foi avaliar a qualidade das águas urbanas em JiParaná/RO e identificar as relações existentes entre a densidade demográfica dasimétrica, uma técnica de refinamento da densidade demográfica tradicional por meio de geoprocessamento, e o Índice de Qualidade das Águas (IQA) em seus igarapés urbanos.

\section{METODOLOGIA}

\section{Área de estudo}

A área em estudo engloba o perímetro urbano da cidade de Ji-Paraná (FIGURA 1), localizada na porção centro-leste do estado de Rondônia, região Norte do Brasil, na Amazônia Ocidental. Disposta na Bacia Hidrográfica do rio Machado (ou Ji-Paraná), sendo essa uma sub-bacia da Bacia Hidrográfica do rio Madeira.

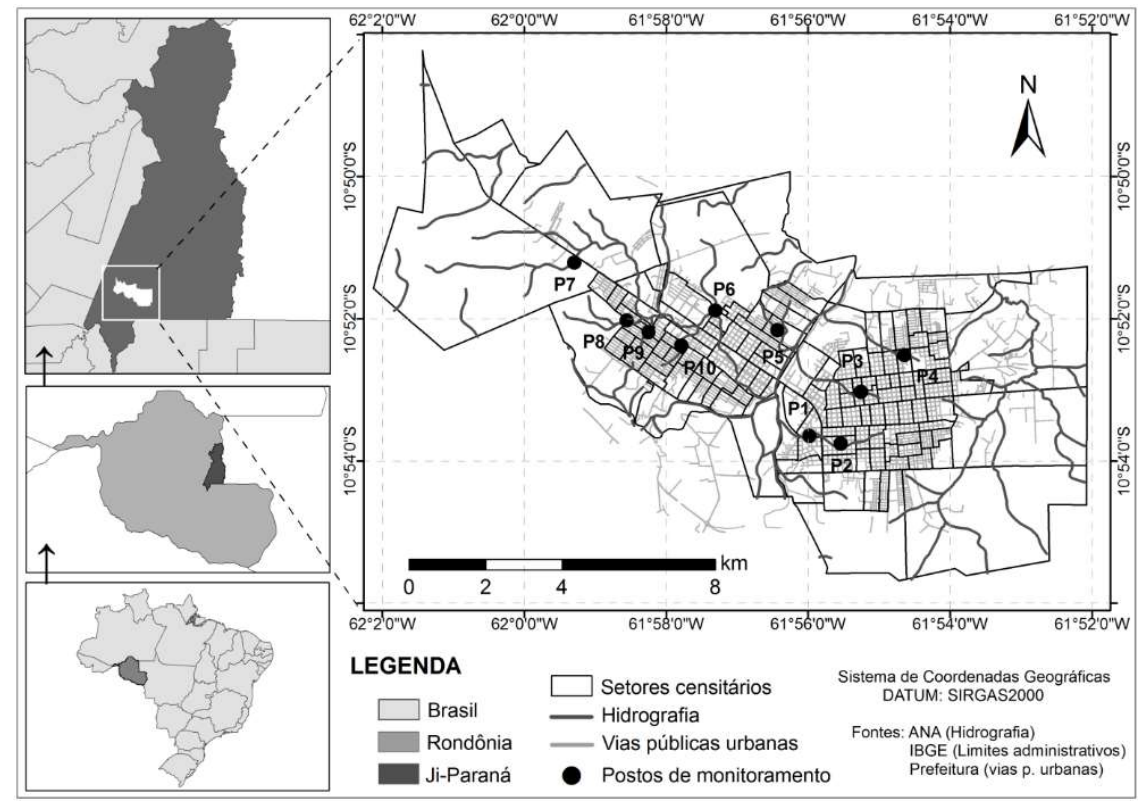

Figura 1: Localização geográfica e hidrografia da cidade de Ji-Paraná/RO.

O objeto de estudo possui, segundo o censo demográfico de 2010 (IBGE, 2010), uma população total de 116.610 habitantes, sendo a população urbana de 102.817 habitantes; e uma área de 114,48 km², com o rio Ji-Paraná (ou rio Machado) dividindo a cidade em dois distritos.

\section{Geoprocessamento}

Tradicionalmente a densidade demográfica é obtida pela razão entre o número de habitantes pela extensão territorial de todo o universo ou, no caso, de todo o perímetro urbano, especializados em mapas coropléticos. Mas esta densidade populacional não retrata totalmente a realidade, visto que há regiões onde a população não habita. Exemplo disso é a densidade demográfica urbana, com a população é distribuída em áreas como campos, matas, rios, parques, entre outros; gerando um efeito de suavização indesejável, distribuindo a população homogeneamente por todo o setor censitário. Assim, recomenda-se a técnica de dasimetria no cálculo de densidade demográfica almejando uma representação mais fiel à realidade por meio 
de integração de dados. Incorporando o mapeamento de uso e cobertura da superfície terrestre da área de interesse no cálculo de densidade demográfica.

Para tanto foram adquiridas imagens do LANDSAT 8/OLI, imageadas em 17/06/2013, apresentando como justificativa de escolha a baixa nebulosidade na área de estudo durante esse período. A classificação da imagem em tipos de cobertura do solo (urbana, água, vegetação primária, vegetação secundária, entre outras) foi realizada em ambiente de Sistema de Informações Geográficas (SIG) do software SPRING 5.2.2 (CÂMARA et al., 1996), com a técnica de classificação supervisionada Bhattacharya, que apresentou melhor desempenho; sendo validada com coletas em campo por meio de um GPS. Cabe destacar que anteriormente a classificação, foi melhorada a resolução espacial para 15 metros por meio de fusionamento das bandas com a banda pancromática. A dasimetria foi determinada em ambiente SIG, suas etapas estão mais detalhadas em pesquisas de Cockx et al. (2015), Nagle et al. (2014), Su et al. (2010) e Zandbergen (2011). A Figura 2 ilustra as etapas desta metodologia.

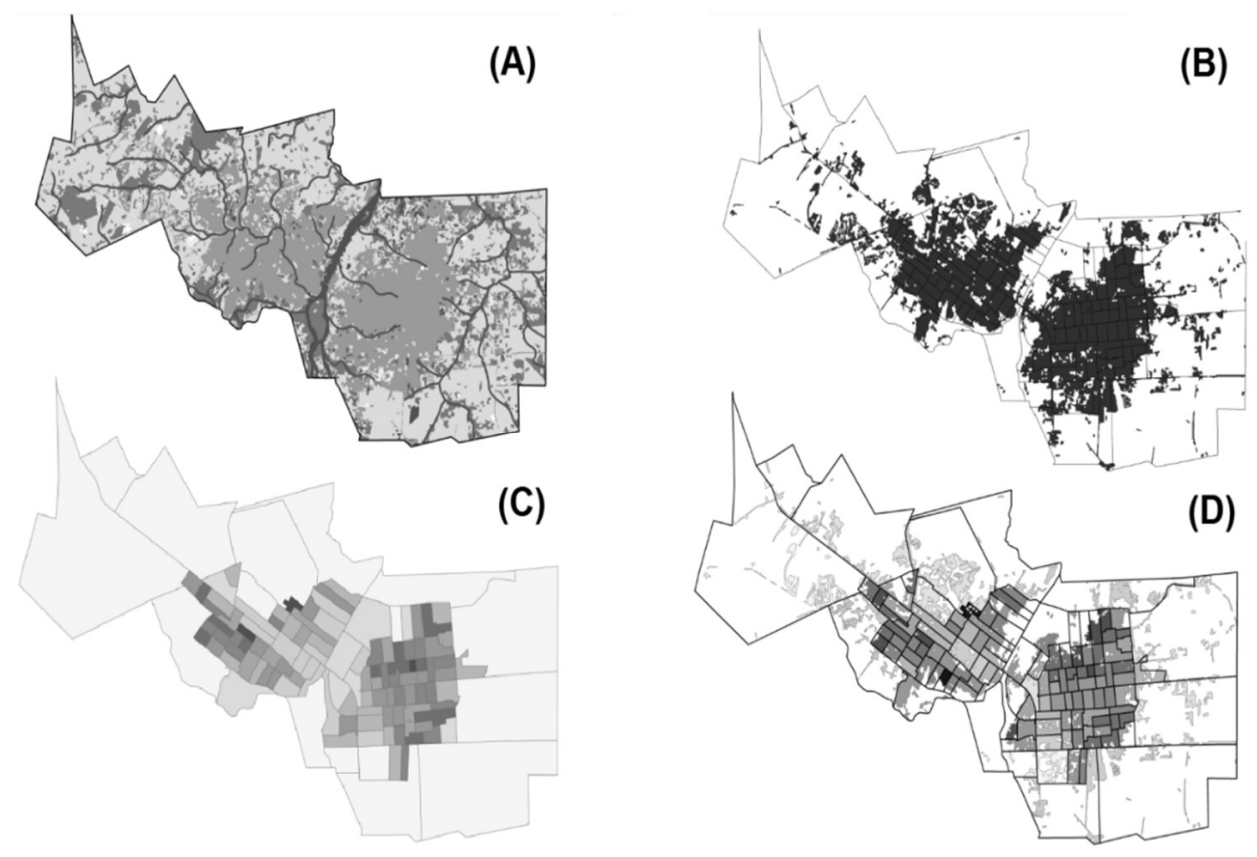

Figura 2: Metodologia da técnica de dasimetria.

Conforme Figura 2, o item (A) retrata a classificação de uso e ocupação do solo, sendo o item (B) a classe 'urbana' extraída deste procedimento. O item (C) refere-se aos setores censitários do Censo Demográfico de 2010 (IBGE, 2010), a definição das áreas destes universos amostrais é conforme metodologia própria do IBGE, no presente estudo foi incluída em cada setor censitário os valores de sua população, dados também obtidos por meio do Censo 2010; gerando portando a densidade demográfica tradicional (população/área). Posteriormente o item (C) foi interpolado com o item (B), redefinindo a área fisicamente habitada pela população urbana. Destarte, o item (D) representa o recálculo da densidade demográfica nas áreas efetivamente habitadas, resultando na densidade demográfica dasimétrica. Após a geração do mapa dasimétrico da área de estudo foram selecionados 10 pontos para coletas de água, de acordo com diferentes classes de densidade demográfica, objetivando a representação de todos seus diferentes níveis (TABELA 1). 
Tabela 1: Informações dos pontos de monitoramento.

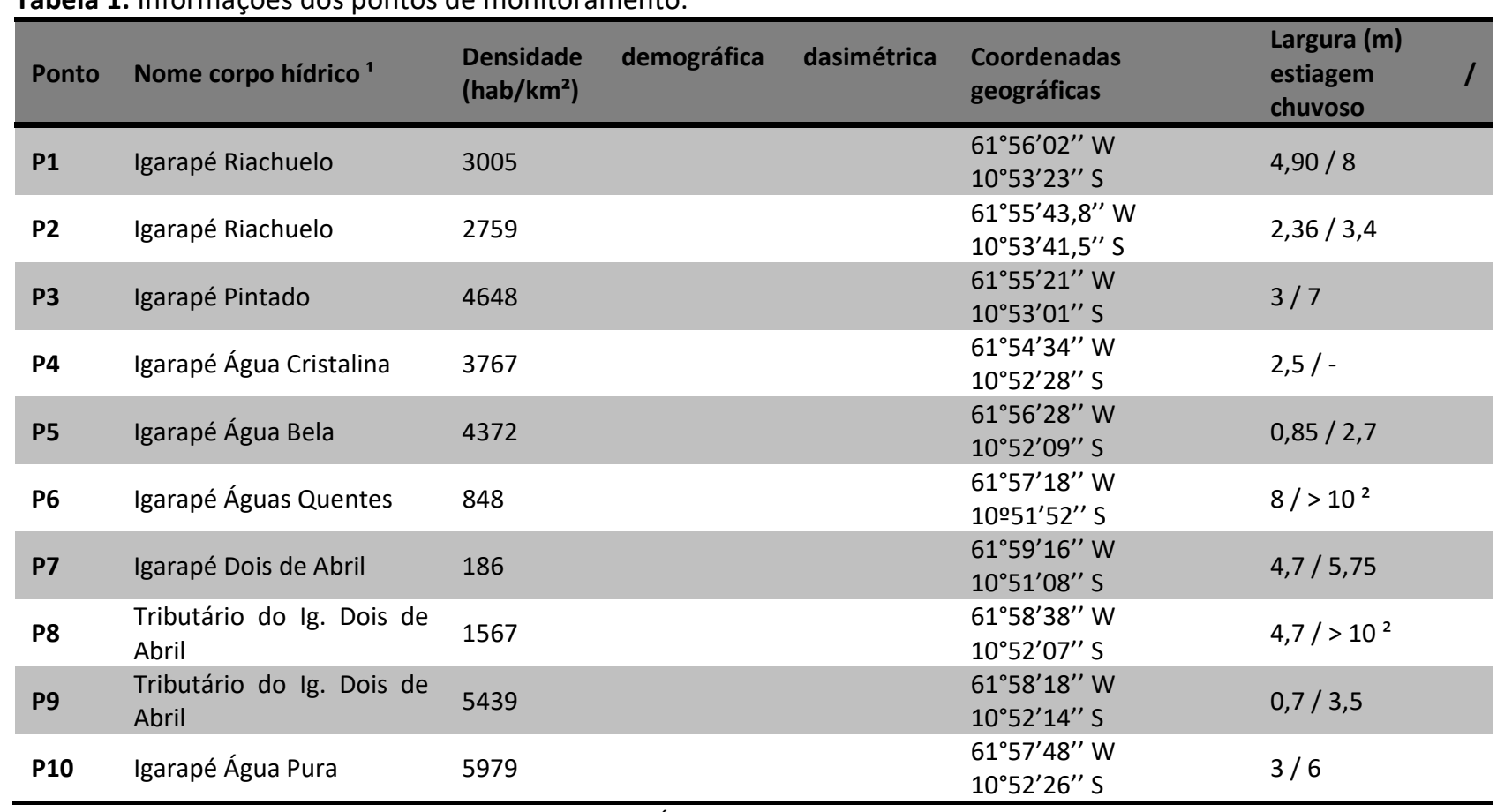

${ }^{1}$ Lei municipal $n^{\circ} 1179$, de 26 de julho de 2002 (JI-PARANÁ, 2002).

${ }^{2}$ Área de zona de inundação, com larguras superiores a 10 metros em período chuvoso.

\section{Índice de Qualidade das Águas Superficiais (IQA)}

Posterior a dasimetria, a qual permitiu a definição dos pontos, foi realizado o monitoramento da qualidade das águas. Nas coletas e preservação das amostras de água foi utilizada a metodologia descrita no Standard Methods for the Examination of Water and Wastewater-SM 1060 (APHA, 2005) e no Guia Nacional de Coleta e Preservação de Amostras (ANA, 2011). Para o cálculo do IQA foram adotados os parâmetros e condições sugeridos pela Agência Nacional de Águas (ANA, 2005), sendo este composto por nove variáveis dos tipos físicas, químicas e microbiológicas. As análises foram realizadas conforme recomendações analíticas internacionais (APHA, 2005) e Normas Brasileiras da ABNT, conforme descrito na Tabela 2.

Tabela 2: Variáveis utilizadas para o cálculo de IQA (ANA, 2005).

\begin{tabular}{lll}
\hline VARIÁVEL & METODOLOGIA & NORMA \\
\hline Coliformes termotolerantes & Técnica da membrana filtrante & SM 9222 (APHA, 2005) \\
\hline Turbidez & Turbidímetro de bancada (TB 1000) & SM 2130 (APHA, 2005) \\
Resíduos totais & Método gravimétrico & NBR 10664 (ABNT, 1989) \\
\hline Temperatura & Termômetro de mercúrio & SM 2550 (APHA, 2005) \\
\hline Demanda Bioquímica de Oxigênio (DBO $\left.{ }_{5,20}\right)$ & Método da incubação com diluição & NBR 12614 (ABNT, 1992a) \\
Fósforo total & Método colorimétrico por redução & NBR 12772 (ABNT, 1992b) \\
Nitrogênio Total Kjedahl (NTK) ${ }^{1}$ & Titulometria & NBR 13796 (ABNT, 1997) \\
Oxigênio Dissolvido (OD) & Método Winkler e sonda de OD & NBR 10559 (ABNT, 1988) \\
\hline Potencial Hidrogeniônico (pH) & Potenciômetro portátil (Orion 250A) & - \\
\hline${ }^{1}$ Valores de NTK foram equiparados aos de Nitrogênio Total (NT) pois, conforme von Sperling (2005), em cursos d'águas com \\
poluições recentes a composição de nitrogênio do meio é basicamente de nitrogênio amoniacal e orgânico (NTK).
\end{tabular}

A série de dados da pesquisa corresponde a coletas mensais de água no período de um ano, de 2013 a 2014, perfazendo oito coletas, respeitando assim a sazonalidade dos corpos hídricos urbanos durante todo o ano de monitoramento, visto que os resultados das variáveis a serem analisadas variam em função do período do ano, sendo a média de duas coletas por período (enchente; chuvoso; vazante e estiagem). As análises laboratoriais foram realizadas nas dependências dos laboratórios de Hidrogeoquímica e de 
Limnologia e Microbiologia (LABLIM) do Departamento de Engenharia Ambiental da Universidade Federal de Rondônia (UNIR).

\section{Análise estatística}

Os dados foram agrupados temporalmente, de acordo com o período sazonal (enchente; chuvoso; vazante e estiagem) em planilhas eletrônicas. Na aplicação dos testes estatísticos foi utilizado o software Action 2.7 da Estatcamp. Para verificar a diferença dos dados entre os períodos do ano, fez uso do teste nãoparamétrico Kruskal-Wallis a nível de significância de $5 \%(\alpha=0,05)$. Para determinar a correlação entre as variáveis densidade demográfica dasimétrica e IQA, foi utilizado o método usualmente conhecido Coeficiente de Correlação Linear de Pearson (PEARSON, 1896). Como pressuposto para confiabilidade dos dados de estatística inferencial, foi aplicado o teste de normalidade pelo método Shapiro-Wilk, com nível de significância de $5 \%$.

\section{RESULTADOS E DISCUSSÃO}

O processo dasimétrico depreendeu que a densidade demográfica na cidade variou entre 73 e 7049 hab/ $\mathrm{km}^{2}$, com os setores censitários mais densos e homogêneos nos núcleos urbanos, e os menos densos e heterogêneos na periferia do perímetro urbano (FIGURA 3).

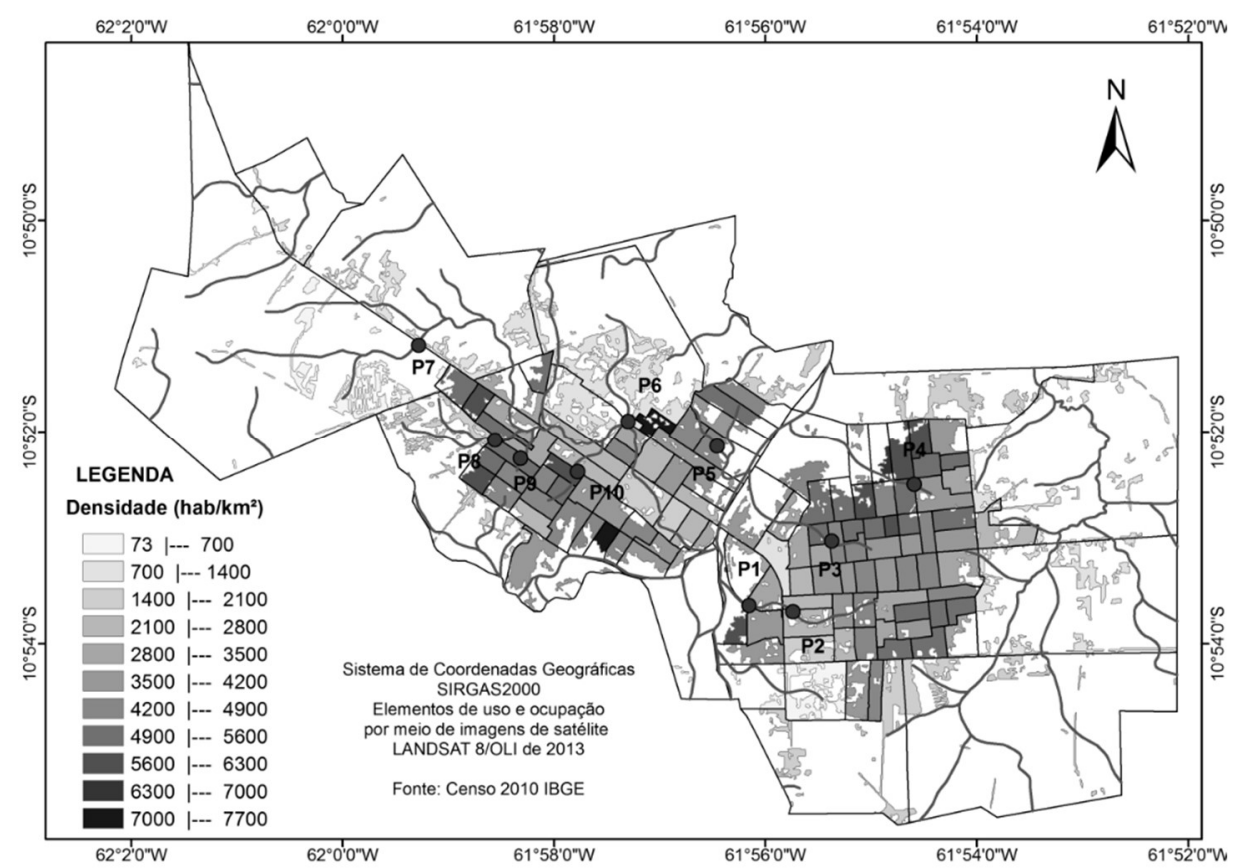

Figura 3: Mapa dasimétrico da densidade demográfica de Ji-Paraná/RO.

Como destacado, os setores periféricos possuem uma menor densidade demográfica, como é o caso do Posto 6 (848 hab/ $\mathrm{km}^{2}$ ) e Posto 7 (186 hab/ $\left.\mathrm{km}^{2}\right)$, isso é justificado pelo fato de serem setores censitários mais novos e possuírem características mais rurais. Enquanto que setores mais densos, a exemplo o Posto 9 (5439 hab/ $\mathrm{km}^{2}$ ) e Posto 10 (5979 hab/ $\mathrm{km}^{2}$ ), se localizam nos núcleos urbanos. Em trabalhos de Eicher et al. (2001), Mennis et al. (2006) e Rocha et al. (2013) esse comportamento também foi encontrado, sendo o esperando, haja vista que a dasimetria retrata dados de área quantitativos usando os limites da divisão da 
área mapeada em zonas de relativa homogeneidade, com o objetivo de melhor retratar a superfície estatística subjacente, e as áreas nos entornos do perímetro urbano possuem classes mais heterogêneas, sendo descartadas durante o processamento (EICHER et al., 2001).

A dasimetria se apresentou como uma robusta ferramenta o um cálculo da densidade demográfica, excluindo áreas que antes eram consideradas nos cálculos, áreas estas como pastos, lagoas e rios, campos, matas etc., ou seja, os polígonos em branco, apresentando assim um resultado mais refinado e fidedigno à realidade. Os valores de IQA apresentaram as seguintes médias e desvios padrão: $18,8 \pm 3,84$ (enchente), $28,8 \pm 2,8$ (chuvoso), $37,1 \pm 6$ (vazante) e $27,8 \pm 5,8$ (estiagem); resultaram numa média geral de $28,2 \pm 9,1$, com um intervalo de confiança de aproximadamente 2,1. Os valores de IQA por ponto amostral e período do ano estão ilustrados na Figura 4.

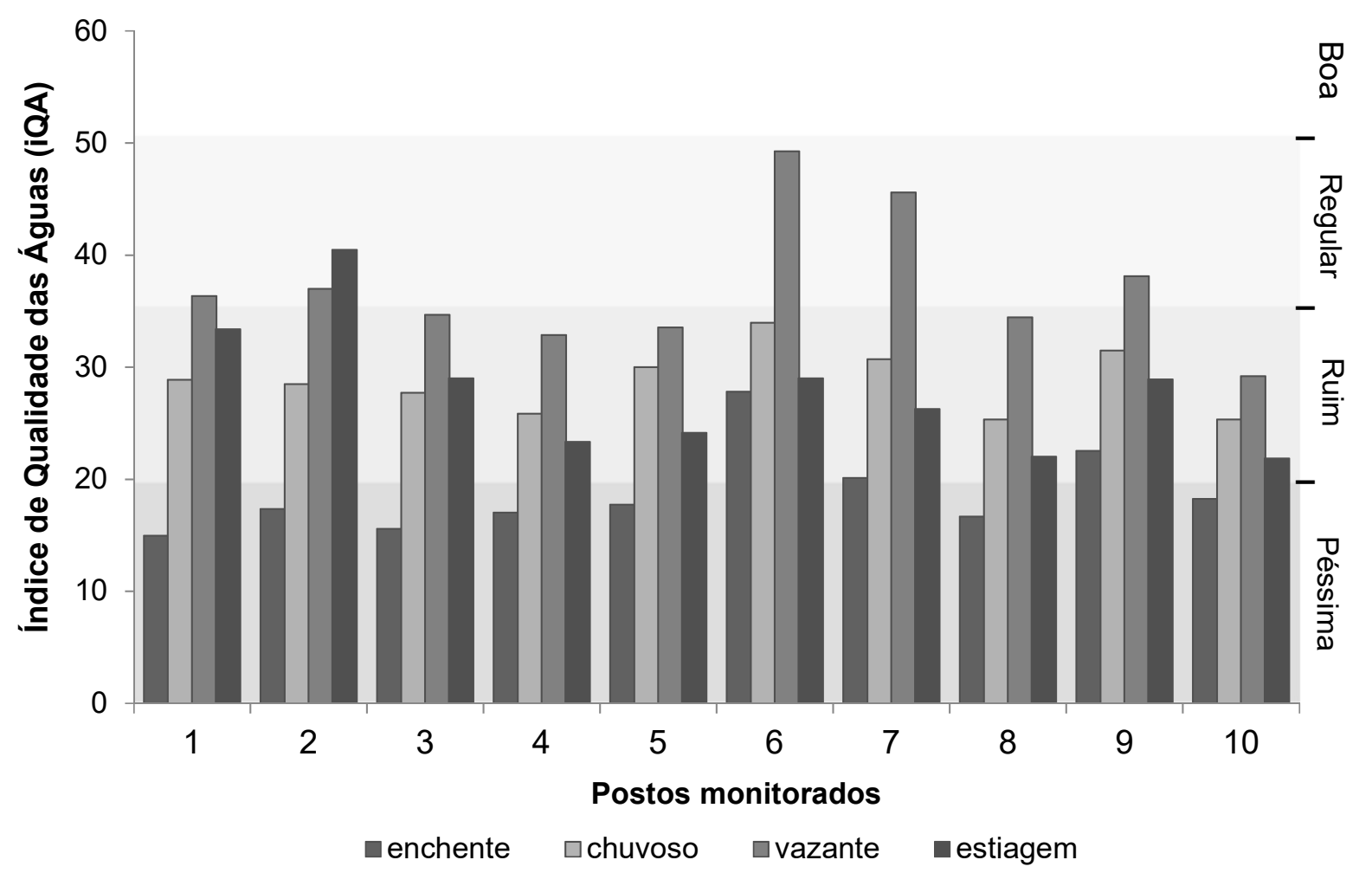

Figura 4: Dados médios de IQA por período do ano, faixas horizontais indicam a classe de qualidade da água: péssima (0-19), ruim (20-36), regular (37-51) e boa (52-79).

$\mathrm{Na}$ análise temporal do conjunto dos dados é notória uma melhoria nos valores IQA de todos os pontos, com uma queda nos valores no período de estiagem, a exceção unicamente do Posto 2. Do conjunto, $70 \%$ dos postos monitorados possuem qualidade péssima no período de enchente, sendo os outros $30 \%$ de classe ruim. Esse período com baixíssima qualidade das águas pode estar associado com uma maior susceptibilidade da lixiviação de cargas poluentes para esses corpos hídricos superficiais durante esse período transitório de início de precipitação, questão abordada em Menezes et al. (2016), Prosab (2009) e Silva et al. (2013), por se tratar de áreas urbanizadas impermeabilizadas (vias, calçadas, pátios, solo compactado, etc.), haja vista que a impermeabilização reduz o coeficiente de infiltração e aumenta a taxa de 
escoamento superficial, fatores atrelados à baixa cobertura sanitária e ao desrespeito com a proteção das APPs.

A origem destes poluentes é diversificada, e contribuem para seu aparecimento a abrasão e o desgaste das vias públicas pelo tráfego veicular, o lixo acumulado nas ruas e calçadas, os resíduos orgânicos de pássaros e animais domésticos, as atividades de construção, resíduos de combustível, óleos e graxas automotivos, poluentes atmosféricos, etc. (BOLLMANN et al., 2006).

No período chuvoso todos os postos se encontram na classe de qualidade ruim, apesar de haver uma melhora na qualidade da água em relação ao período anterior (péssima), ainda assim os igarapés analisados apresentam uma baixa qualidade, indicando outras formas de depleção da água, paralelas à lixiviação de poluentes, como descarte irregular de resíduos urbanos, descargas de efluentes sanitários in natura diretamente nessas águas, entre outros. Pesquisa de Viana et al. (2013), realizada em ambiente lêntico (lagoa), também constatou uma melhora nos valores de IQA no período chuvoso, quando comparados com período seco (estiagem).

Marques et al. (2012) relacionam os valores de IQA com proximidades às áreas de disposição de resíduos urbanos, em estudo comparativo do IQA das águas superficiais próximas a distintas formas de disposição (lixão, aterro controlado e aterro sanitário) apontaram valores de IQA de classe ruim para rio próximo ao lixão, IQA classe média para rios próximos aos aterros controlados e sanitários, sendo que o que colaborou para uma menor qualidade nas águas dos aterros sanitários foi a identificação de descargas de esgotos. Corroborando para as observações sobre os efeitos do lançamento de resíduos urbanos diretamente nas águas que acarretam em sua deterioração.

O período que apresentou maiores índices de IQA foi o de vazante, contribuindo para as discussões sobre os efeitos que a chuva exerce, sendo que nesse período ela favorece a melhoria na qualidade da água devido à diluição da concentração de poluentes e no aumento do $\mathrm{OD}$, com redução nas concentrações de coliformes, turbidez, resíduo total, DBO e fósforo total. Ainda assim a qualidade das águas neste período não é satisfatória, com $50 \%$ dos pontos em classe tipo ruim e $50 \%$ situados em classe regular.

A respeito da redução dos valores de IQA no período de estiagem, há duas hipóteses. A primeira é que uma chuva registrada dias anteriores à coleta do mês de setembro possa ter interferido nos resultados para esse período, ainda, as análises microbiológicas do mês de agosto apresentaram problemas e foi preferível o descarte desta campanha, impossibilitando o cálculo do IQA no referido mês, sendo esse período representado por uma campanha de coleta. A segunda, sendo a mais provável, devido a comportamentos semelhantes na análise das variáveis isoladamente, com a estiagem as vazões dos corpos hídricos reduziram, aumentando a concentração dos poluentes oriundos de outras formas de poluição além da lixiviação superficial. Nas comparações múltiplas ente os conjuntos de dados temporais (TABELA 3), foram identificadas diferenças entre o período enchente (piores índices de qualidade) com todos os demais períodos, e entre os períodos chuvoso e vazante. 
Tabela 3: Comparações múltiplas dos dados de Índice de Qualidade das Águas (IQA) entre os períodos do ano pelo método de Kruskal-Wallis ( $\mathrm{n}=20$, por período *).

\begin{tabular}{llll}
\hline Fatores comparados & Diferença observada & Diferença crítica & Diferença \\
\hline estiagem - enchente & 22,40 & 20,79 & Sim \\
estiagem - chuvoso & 2,75 & 20,79 & Não \\
estiagem - vazante & 20,00 & 20,79 & Não \\
enchente - chuvoso & 25,15 & 16,98 & Sim \\
enchente - vazante & 42,40 & 16,98 & Sim \\
chuvoso - vazante & 17,25 & 16,98 & Sim \\
\hline
\end{tabular}

* A exceção do período de estiagem, com $n=10$.

A correlação entre as variáveis densidade populacional e IQA elencou os seguintes resultados: $\rho=-$ 0,30 no período de enchente; $\rho=-0,35$ para o chuvoso; $\rho=-0,75$ na vazante; e $\rho=-0,14$ para período de estiagem. Como observado, todas foram negativas, indicando que são inversamente proporcionais, ou seja, infere-se que o aumento da densidade populacional implica na redução da qualidade das águas superficiais. Reafirmando, com base nos dados aferidos, uma relação de deterioração da qualidade provinda da densidade demográfica. Para Kuss et al. (2016) essa constatação foi evidenciada no monitoramento da qualidade do rio Palmital, destacando que o posto com características mais naturais e menor densidade populacional apresentou melhor qualidade quando comparado a outro posto disposto numa região mais urbanizada e densa. Demais pesquisas com fins de avaliar os efeitos da urbanização na qualidade das águas superficiais também foram abordados por Cornelli et al. (2016), Durigon et al. (2015), Ribeiro et al. (2010), Souza et al. (2014) e Ternus et al. (2011).

Apesar de apenas o período de vazante apresentar uma forte correlação entre a densidade demográfica dasimétrica e os valores de IQA, enquanto os demais períodos apresentam fraca correlação, é importante destacar que o coeficiente utilizado considera uma análise linear entre as variáveis, podendo a relação entre as variáveis ser não linear ou, até mesmo, sofrer interferência de outras variáveis ambientais. Estudos cotejando estatisticamente a qualidade da água e a densidade populacional são escassos. Bollmann (2003) em estudos de regressão em três microbacias hidrográficas distintas do país, pelo método tradicional de densidade demográfica, encontrou valores expressivos $\left(R^{2}>0,88\right)$ para as variáveis de compostos nitrogenados (NTK, amoniacal e orgânico), fósforo total, DBO, Demanda Química de Oxigênio (DQO), Resíduos Totais, Condutividade Elétrica e pH; denotando o reflexo que as atividades antrópicas exercem sobre a qualidade do meio ambiente natural.

\section{CONCLUSÕES}

Os resultados apontaram uma amplitude de aproximadamente $7000 \mathrm{hab} / \mathrm{km}^{2}$ dentre as classes de densidade demográfica dasimétrica na cidade de Ji-Paraná, com setores censitários mais densos em áreas centrais do perímetro urbano. Quanto à qualidade das águas urbanas, no período em estudo nenhum corpo hídrico apresentou qualidade boa, estando a maioria com qualidade péssima e ruim. As correlações negativas da densidade demográfica dasimétrica com o IQA indicam uma relação de depleção na qualidade dos igarapés da cidade em decorrência do aumento da concentração populacional, com maior nível de sensibilidade no período de vazante, evidenciando uma correlação fortemente negativa $(\rho=-0,75)$. Apesar da 
baixa qualidade dos igarapés urbanos de Ji-Paraná, os danos diretos da densidade populacional são difíceis de serem mensurados estatisticamente. São diversos e complexos aspectos envolvidos nesse vínculo e nem sempre se baseiam em associação linear direta.

Os problemas decorrentes de um processo de ocupação urbana desordenado são sinérgicos, a questão da baixa qualidade dos corpos hídricos urbanos superficiais não é uma exceção, sendo afetada direta e indiretamente por diferentes aspectos, expressando assim a necessidade de intervenção pelo poder público de melhorar essa relação de interação homem e meio ambiente por meio de infraestruturas urbanas sustentáveis. Espera-se que o presente trabalho sirva de contribuição para novas pesquisas voltadas ao tema de qualidade das águas urbanas decorrentes das formas de uso e ocupação do solo e a intensidade com que as atividades antrópicas influenciam na qualidade das águas superficiais.

\section{REFERÊNCIAS}

ABNT. Associação Brasileira de Normas Técnicas. NBR 13796: Água: Determinação de nitrogênio orgânico, Kjeldahl e total Métodos macro e semimicro Kjeldahl. Rio de Janeiro: ABNT, 1997.

ABNT. Associação Brasileira de Normas Técnicas. NBR 12614: Águas: Determinação da Demanda Bioquímica de Oxigênio (DBO). Método de incubação ( $20{ }^{\circ} \mathrm{C}$, cinco dias). Rio de Janeiro: ABNT, 1992a.

ABNT. Associação Brasileira de Normas Técnicas. NBR 12772: Água: Determinação de fósforo. Rio de Janeiro: ABNT, 1992b.

ABNT. Associação Brasileira de Normas Técnicas. NBR 10664: Águas: Determinação de resíduos (sólidos): Método Gravimétrico. Rio de Janeiro: ABNT, 1989.

ABNT. Associação Brasileira de Normas Técnicas. NBR 10559: Águas: Determinação de Oxigênio Dissolvido. Método lodométrico Winkler e suas modificações. Rio de Janeiro: ABNT, 1988.

ANA. Portaria no 149, de 26 de março de 2015: Dispõe sobre lista de termos para o thesaurus de recursos hídricos da Agência Nacional de Águas. Brasília: ANA, 2015.

ANA. Guia Nacional de Coleta e Preservação de Amostras: água, sedimento, comunidade aquática e efluentes líquidos. São Paulo: CETESB; Brasília: ANA, 2011.

ANA. Panorama da qualidade das águas superficiais no Brasil: Caderno de Recursos Hídricos 1. Brasília: ANA, 2005.

APHA. American Public Health Association. Standard Methods for the examination of water and wastewater: SM-1060: Collection and Preservation of Samples. 21 ed. Washington: APHA, 2005.

APHA. American Public Health Association. Standard Methods for the examination of water and wastewater: SM-2130: Turbidity. 21 ed. Washington: APHA, 2005.

APHA. American Public Health Association. Standard Methods for the examination of water and wastewater: SM-2550: Temperature. 21 ed. Washington: APHA, 2005.
APHA. American Public Health Association. Standard Methods for the examination of water and wastewater: SM-9222: Membrane Filter Technique for members of the coliform group. 21 ed. Washington: APHA, 2005.

BOLLMANN, H. A.; MARQUES, D. M. L. M.. Influência da densidade populacional nas relações entre matéria orgânica carbonácea, nitrogênio e fósforo em rios urbanos situados em áreas com baixa cobertura sanitária. Engenharia Sanitária e Ambiental, Rio de Janeiro, v.11, n.4, p.343-352, 2006.

BOLLMANN, H. A.. Relação da densidade populacional sobre variáveis de qualidade físico-química das águas superficiais em microbacias hidrográficas sem cobertura sanitária em Porto Alegre/RS. Tese (Doutorado em Engenharia de Recursos Hídricos e Saneamento Ambiental) Universidade Federal do Rio Grande do Sul, Porto Alegre, 2003.

BRITANNICA. Igarapé. Rio de Janeiro: Britannica Escola, 2017.

CÂMARA, G.; SOUZA, R. C. M.; FREITAS, U. M.; GARRIDO, J.. Spring: Integrating remote sensing and GIS by objectoriented data modelling. Computers \& Graphics, v.20, n.3, p.395-403, 1996.

COCKX, K.; CANTERS, F.. Incorporating spatial nonstationarity to improve dasymetric mapping of population. Applied Geography, v.63, n.1, p.220-230, 2015.

CORNELLI, R.; SCHNEIDER, V. E.; BORTOLIN, T. A.; CEMIN, G.; SANTOS, G. M.. Análise da Influência do Uso e Ocupação do Solo na Qualidade da Água de Duas Sub-Bacias Hidrográficas do Município de Caxias do Sul. Scientia cum Industria, v.4, n.1, 2016. DOI:

http://dx.doi.org/10.18226/23185279.v4iss1p1

DAMASCENO, M. C. S.; RIBEIRO, H. M. C.; MORGANNE, C.; TAKIYAMA, L. R.; PAULA, M. C.. Avaliação sazonal da qualidade das águas superficiais do Rio Amazonas na orla da cidade de Macapá, Amapá, Brasil. Rev. Ambient. Água, Taubaté, v.10, n.3, p.598-613, 2015. Dol: http://dx.doi.org/10.4136/ambi-agua.1606 
DURIGON, M.; OLIVEIRA, M. A.; WOLFF, D. B.; CASSOL, A. P. V.; SILVA, J. F.. A urbanização compromete a qualidade da água da bacia hidrográfica dos rios Vacacaí e Vacacaí-Mirim em Santa Maria, RS. Ciência e Natura, Santa Maria, v.37, n.4, p.64-73, 2015. DOI:

http://dx.doi.org/105902/2179460X17395

EICHER, C. L.; BREWER, C. A.. Dasymetric Mapping and Areal Interpolation: Implementation and Evaluation. Cartography and GeograPhic Information Science, v.28, n.2, p.125-138, 2001.

FIA, R.; TADEU, H. C.; MENEZES, J. P. C.; FIA, F. R. L.; OLIVEIRA, L. F. C.. Qualidade da água de um ecossistema lótico urbano. Revista Brasileira de Recursos Hídricos, Porto Alegre, v.20, n.1, p.267-275, 2015.

FIDELIS, L.; NESSIMIAN, J. L.; HAMADA, N.. Distribuição espacial de insetos aquáticos em igarapés de pequena ordem na Amazônia Central. Acta Amaz.,

Manaus, v.38, n.1, p.127-134, 2008. DOI:

http://dx.doi.org/10.1590/S0044-59672008000100014

GARCIAS, C. M.. Experiências na revitalização do Rio Belém: Realidades urbanas do Brasil. GESTA, Salvador, v.4, n.1, p.5068, 2016. DOI: http://dx.doi.org/10.9771/gesta.v4i1.14910

GORSKI, M. C. B.. Rios e cidades: ruptura e reconciliação. São Paulo: Editora Senac São Paulo, 2010.

IBGE. Instituto Brasileiro de Geografia e Estatística. Censo Demográfico 2010: Manual do Recenseador. Rio de Janeiro: IBGE, 2010.

JI-PARANÁ. Lei n.1179, de 26 de julho de 2002. Dispõe sobre a denominação dos igarapés existentes na área urbana do município. Atos oficiais, 2002.

KUSS, C. P.; CASTRO, F. B. G.. Avaliação da qualidade físicoquímica e microbiológica das águas do rio Palmital em Colombo-PR. Cadernos da Escola da Saúde, Curitiba, v.1, n.15, p.32-41, 2016.

LEMOS, M.; FERREIRA NETO, M.; DIAS, N. S.. Sazonalidade e variabilidade espacial da qualidade da água na Lagoa do Apodi, RN. Rev. bras. eng. agríc. ambient., Campina Grande, v.14, n.2, p.155-164, 2010. DOI: http://dx.doi.org/10.1590/S1415-43662010000200006

LOPES, F. P.; TEIXEIRA, A. S.; ANDRADE, E. M.; AQUINO, D. N.; ARAÚJO, L. F. P.. Map of Acaraú River water quality by the use of WQI and GIS. Revista Ciência Agronômica, Campina Grande, v.39, n.3, p.392-402, 2008.

MAANE-MESSAI, S.; LAIGNEL, B.; MOTELAY-MASSEI, A.; MADANI, K.; CHIBANE, M.. Spatial and temporal variability of water quality of an urbanized river in Algeria: The case of Soummam Wadi. Water Environment Research, Washington, v.82, n.8, p.742-749, 2010.

MARQUES, R. F. P. V.; SILVA, A. M.; RODRIGUES, L. S.; COELHO, G.. Impacts of urban solid waste disposal on the quality of surface water in three cities of Minas Gerais/Brazil. Ciência e Agrotecnologia, Lavras, v.36, n.6, p.684-692, 2012.
MENEZES, J. P. C.; BITTENCOURT, R. P.; FARIAS, M. S.; BELLO I. P.; FIA, R.; OLIVEIRA, L. F. C.. Relationship between patterns of use and occupation of soil and water quality in an urban watershed. Eng. Sanit. Ambient., Rio de Janeiro, v.21, n.3, p.519-534, 2016. DOI: http://dx.doi.org/10.1590/S1413-41522016145405.

MENNIS, J.; HULTGREN, T.. Intelligent dasymetric mapping and its application to areal interpolation.

Cartography and Geographic Information Science, [S.I.], v.33, n.3, p.179-194, 2006.

MORAIS, P. R. F; OLIVEIRA, T. M. B. F; SOUZA, L. D; CASTRO, S. S. L.. Determinação do IQA nas águas da bacia hidrográfica Apodi/Mossoró em regiões de baixa e alta influência da zona urbana. In: CONGRESSO NORTE NORDESTE DE QUÍMICA, 3. Anais. São Luís: CNNQ, 2009.

NAGLE, N. N.; BUTTENFIELD, B. P.; LEYK, S.; SPIELMAN, S.. Dasymetric Modeling and Uncertainty. Annals of the Association of American Geographers, v.104, n.1, p.80-95, 2014.

OLIVEIRA, L. N.. Estudo da variabilidade sazonal da qualidade da água do rio Poti em Teresina e suas implicações para a população local. Dissertação (Mestrado em Desenvolvimento e Meio Ambiente) - Universidade Federal do Piauí, Teresina, 2012

PEARSON, K.. Mathematical contributions to the theory of evolution. III. Regression, heredity, and panmixia. Philosophical Transactions of the Royal Society of London, v.187, p.253-318, 1986.

PEREIRA, A. R.; SANTOS, A. A.; SILVA, W. T. P.; FROZZI, J. C.; PEIXETO, K. L. G.. Avaliação da qualidade da água superficial na área de influência de um lixão. Rev. Ambient. Água, Taubaté, v.8, n.3, p.239-246, 2013.

PINTO FILHO, J. L. O.; SANTOS, E. G.; SOUZA, M. J. J. B.. Proposta de Índice de Qualidade de Água para a lagoa do Apodi/RN, Brasil. HOLOS, v.2, n.1, p.69-76, 2008.

PROSAB. Manejo de Águas Pluviais Urbanas. Rio de Janeiro: ABES, 2009.

RIBEIRO, M. R.; SOUZA, S. R.; MUNIZ, D. H. F.; SILVA, M. C.; OLIVEIRA-FILHO, E. C.. Caracterização microbiológicae físicoquímica de águas superficiais em parques urbanos no Distrito Federal. Ciências da Saúde, Brasília, v.8, n.2, p.1534, 2010. DOI: http://dx.doi.org/10.5102/ucs.v8i2.1302

ROCHA, V. N. L.; SANTOS, A. M.. Cálculo da densidade demográfica da cidade de Vilhena/RO através do método dasimétrico. In: ENCONTRO NACIONAL DE ESTUDANTES DE ENGENHARIA AMBIENTAL, 11. Anais. São Paulo: ENEEAmb, 2013.

SILVA, A. G.; SOUZA, L. D.. Efeitos antrópicos e sazonais na qualidade da água do rio do Carmo. HOLOS, v.5, p.122-136, 2013. DOI: http://dx.doi.org/10.15628/holos.2013.1197

SU, M. D.; LIN, M. C.; HSIEH, H. I.; TSAI, B. W.; LIN, C. H.. Multi-layer multi-class dasymetric mapping to estimate population distribution. Science of the Total Environment, v.408, p.4807-4816, 2010. 
SOUZA, M. M.; GASTALDINI, M. C. C.. Water quality assessment in watersheds with different anthropogenic impacts. Eng. Sanit. Ambient., Rio de Janeiro, v.19, n.3, p.263-274, 2014.

DOI: http://dx.doi.org/10.1590/S141341522014019000001097

TERNUS, R. Z.; SOUZA-FRANCO, G. M.; ANSELMINI, M. E.K.; MOCELLIN, D. J. C.; DAL MAGRO, J.. Influence of urbanisation on water quality in the basin of the upper Uruguay River in western Santa Catarina, Brazil. Acta Limnol. Bras., Rio Claro, v.23, n.2, p.189-199, 2011. DOI: http://dx.doi.org/10.1590/S2179-975X2011000200009
VIANA, L. G.; DIAS, D. F. S.; OLIVEIRA, V. P. S.; MOREIRA, M. A. C.. Índice de Qualidade da Água (IQA) da Lagoa do Taí, São João da Barra/RJ. Boletim do Observatório Ambiental Alberto Ribeiro Lamego, Campos dos Goytacazes, v.7 n.2, p.199-219, 2013. DOI: http://dx.doi.org/10.5935/21774560.20130022

VON SPERLING, M.. Introdução à qualidade das águas e ao tratamento de esgotos. 3 ed. Belo Horizonte: DESA-UFMG, 2005.

ZANDBERGEN, P. A.. Dasymetric Mapping Using High Resolution Address Point Datasets. Transactions in GIS, v.15, n.1, p.5-27, 2011. DOI: http://dx.doi.org/10.1111/j.1467$\underline{9671.2011 .01270 . x}$

A CBPC - Companhia Brasileira de Produção Científica (CNPJ: 11.221.422/0001-03) detém os direitos materiais desta publicação. Os direitos referem-se à publicação do trabalho em qualquer parte do mundo, incluindo os direitos às renovações, expansões e disseminações da contribuição, bem como outros direitos subsidiários. Todos os trabalhos publicados eletronicamente poderão posteriormente ser publicados em coletâneas impressas sob coordenação da Sustenere Publishing, da Companhia Brasileira de Produção Científica e seus parceiros autorizados. Os (as) autores (as) preservam os direitos autorais, mas não têm permissão para a publicação da contribuição em outro meio, impresso ou digital, em português ou em tradução. 